\title{
Food sensitization and food allergy in allergic Thai patients from a tertiary care center in Thailand
}

\author{
Chaweewan Sripramong, ${ }^{1}$ Kittipos Visitsunthorn, ${ }^{2}$ Witchaya Srisuwatchari, ${ }^{1}$ Panchama Pacharn, ${ }^{1}$ \\ Orathai Jirapongsananuruk, ${ }^{1}$ Nualanong Visitsunthorn ${ }^{1}$
}

\begin{abstract}
Background: A skin prick test (SPT) and food challenge test (OFC) are useful in identification of food sensitization and food allergy.
\end{abstract}

Objective: To evaluate food allergen sensitization by SPT and food allergy by OFC in allergic Thai patients

Methods: SPTs for common food allergens were performed on allergic patients at Siriraj Hospital, Bangkok, Thailand, from 2011 to 2015. An OFC was performed in positive food SPT patients with informed consent.

Results: SPTs to food were positive in 539 (20\%) out of 2,678 allergic patients ( $73.8 \%$ were $<10$ years old). Crab was the most common sensitized food in each year of the study period. In patients aged $<1$ year, the most common sensitized foods were egg white $(23.8 \%)$ and wheat (22.2\%), while shrimp was for patients aged $>10$ years (25\%). A positive OFC was found in $29(26.1 \%)$ out of the 111 OFCs performed (9.1\% in patients with asthma, $28.6 \%$ in allergic rhinitis and $26.3 \%$ in food allergy). Positive OFCs were found for $60 \%$ of the crab, $35.7 \%$ of the egg yolk, and $31 \%$ of the cow's milk OFCs. Compared to OFC, SPT showed high specificity $(71 \%-100 \%)$ but low sensitivity $(0 \%-40 \%)$. The percentage of sensitization to egg white, egg yolk, wheat, soy, and peanut significantly increased $(p<0.05)$ from 2011 to 2015.

Conclusion: The sensitization to egg white, egg yolk, wheat, soy, and peanut significantly increased and crab was the most common sensitized food. Food allergy in patients with allergic rhinitis was as common as in patients diagnosed food allergy.

Key words: Food sensitization, food allergy, skin prick test, oral food challenge test, allergic patients

\section{Citation:}

Sripramong, C., Visitsunthorn, K., Srisuwatchari, W., Pacharn, P., Jirapongsananuruk, O., Visitsunthorn, N. (2022). Food sensitization and food allergy in allergic Thai patients from a tertiary care center in Thailand. Asian Pac J Allergy Immunol, 40(2), 148-155. https://doi.org/10.12932/ap-210119-0475

\section{Affiliations:}

Division of Allergy and Clinical Immunology, Department of Pediatrics, Faculty of Medicine, Siriraj Hospital, Mahidol University, Bangkok, Thailand

2 Saint Louis University School of Medicine, Saint Louis, Missouri, USA

\section{Corresponding author:}

Nualanong Visitsunthorn

Division of Allergy and Immunology, Department of Pediatrics,

Faculty of Medicine, Siriraj Hospital, Mahidol University,

2 Wanglang Rd, Bangkoknoi, Bangkok 10700, Thailand

E-mail: nualanongv@yahoo.com

Abbreviations/Acronyms:
$\begin{array}{ll}\text { SPT } & \text { skin prick test } \\ \text { OFC } & \text { oral food challenge test } \\ \text { MWD } & \text { mean wheal diameter }\end{array}$

\section{Introduction}

Allergic disease, one of the most common non-communicable diseases, is a major health problem around the world. The prevalence of allergic diseases has increased worldwide over the last three decades. ${ }^{1,2}$ The atopic march starts with food allergies before turning to respiratory allergies. Allergen exposure causes sensitization and the development of allergy symptoms in allergy-prone children. ${ }^{3}$ Common foods that cause sensitization in Thais are cow's milk, egg white, and seafood, followed by egg yolk, wheat, soy, and peanut. ${ }^{4,5}$

Allergen sensitization is demonstrated by the presence of a specific immunoglobulin E (sIgE) to allergens, which can be demonstrated in vivo by an allergen skin prick test (SPT) and in vitro by serum sIgE quantification. The SPT is an approved 
and validated tool for evaluating allergic sensitization in patients with atopic diseases. It is simple, accurate, safe, and less expensive than an sIgE measurement. ${ }^{6}$ The incidence of adverse reactions related to SPTs is usually not more than $0.04 \%,{ }^{7}$ and the reactions are usually mild. No fatal cases related to the aeroallergen SPT have been reported. ${ }^{6-8} \mathrm{~A}$ previous study in 5,879 Thai patients showed no adverse systemic reactions from 82,306 SPTs. ${ }^{9}$

Local food allergen extracts prepared by the Division of Pediatric Allergy, Faculty of Medicine, Siriraj Hospital, Mahidol University, Bangkok, Thailand, have proven to be useful for the diagnosis of food sensitization measured by an SPT. These local food extracts showed superior results to commercial food extracts when the extracts were compared using an oral food challenge test (OFC) as the gold standard. ${ }^{10-11}$

This study aimed to evaluate food allergen sensitization by SPT and OFC in allergic Thai patients from the year 2011 to 2015.

\section{Methods}

SPTs were performed on Thai patients who had been clinically diagnosed with an allergy and referred to the Pediatric Allergy Clinic, Siriraj Hospital, Mahidol University, Bangkok, Thailand, between 2011 and 2015. The study was approved by the Institutional Ethics Board Committee and registered with ClinicalTrials.gov (NCT03645629). The characteristics of the patients, comprising age, sex, age of onset, and severity of the allergic diseases, were reviewed. All of the study patients underwent an SPT with commercial extracts (ALK-Abello, New York, USA) of common food allergens in Thailand (egg white, egg yolk, cow's milk, soy, crab, oyster, and clam) and lyophilized local food extracts (shrimp and wheat). Excluded were patients who were pregnant, or who had acute asthma exacerbation, severe skin diseases, or chronic diseases (such as autoimmune disease, immune deficiency, and cancer). The use of antihistamines, systemic corticosteroids ( $\geq 20 \mathrm{mg} /$ day), and topical corticosteroids was discontinued for at least 7 days before testing.

The severity of asthma was classified according to the Global Initiative for Asthma guidelines. ${ }^{12}$ In addition, the severity of allergic rhinitis was classified according to the Allergic Rhinitis and its Impact on Asthma guidelines. ${ }^{13}$

The skin tests were performed with single-use metal lancets (Vitrex steel, Vitrex Medical A/S, Herlev, Denmark) by trained health professionals. Histamine dihydrochloride (10 $\mathrm{mg} / \mathrm{ml}$ ) and a $50 \%$ glycerosaline solution were used as the positive and negative controls, respectively. As to the pricking method, the needle was passed through the drop of extract before pricking the epidermis. The results were recorded 10 minutes after the histamine skin test and 15 minutes after the food allergen SPT. The mean wheal diameter (MWD) of each extract was calculated by adding the longest diameter of the wheal and the perpendicular diameter, and dividing the resulting sum by two. The SPT result was defined as positive if the MWD was at least $3 \mathrm{~mm}$ larger than the MWD of the negative control.
Monosensitization to food was recorded if a patient had only one kind of food allergen sensitization, while polysensitization to food was recorded if a patient had more than one kind of food allergen sensitization. In the patients with positive SPT to at least one food, the OFCs were performed to the food with positive SPT and the food with negative SPT that the parents accepted to do. An OFC was performed in the hospital. All of the patients who underwent an SPT and an OFC were required to give their written informed consent before the procedures were conducted.

Correlations between the age of onset, the severity of diseases, and allergen sensitization (number of positive SPTs and the MWDs) were performed. Evaluations were made of the sensitivities, specificities, accuracies, and likelihood ratios +/of the SPTs compared to the OFCs as the gold standard.

\section{Statistical analysis}

The statistical analysis was performed using PASW Statistics for Windows, version 18.0 (SPSS Inc., Chicago, IL, USA). The characteristics data were presented as median (range) for continuous data, or as number and percentage for categorical data. The chi-square test was used to compare categorical variables. Evaluations of the trends were made using the chi-squared for trend. The Mann-Whitney $U$ test was used to compare the non-normal distribution variables between groups. The correlations between the age of onset, disease severity, and MWD were analyzed with Spearman's rho correlation. A $p$-value of $<0.05$ was considered to denote statistical significance.

\section{Results}

SPTs using food allergens were performed in 2,678 allergic patients. The SPTs were positive in 539 patients, and 111 OCTs were subsequently performed (Figure 1). In OFC performing, 20 tests were done in the patients with positive SPT to tested foods and 91 tests were done in the patients with negative SPT to tested foods. OFC was positive in 6 tests (30\%) with SPT positive to tested food and in 22 tests $(24.2 \%)$ with negative SPT to tested food. The clinical characteristics of the participants are at Table 1. Sixty-one percent of the participating individuals were male. The most common diagnoses were allergic rhinitis $(77 \%)$ and asthma (16.9\%). Of the allergic rhinitis severities, $56.8 \%$ were mild persistent, $21.2 \%$ mild intermittent, $18.6 \%$ moderate to severe intermittent, and $3.3 \%$ moderate to severe persistent. As to the asthma severities, $47.3 \%$ were mild persistent, $32.7 \%$ moderate persistent, $11.9 \%$ mild intermittent, and $8 \%$ severe persistent. Food allergy was diagnosed in $7.1 \%$ of the participants. The age distribution showed that $73.8 \%$ of patients were under 10 years of age, and $96.4 \%$ were under 15 , with a mean of 7.2 years and a median of 6.5 years ( $0.1-29$ years). Only 8 patients $(0.3 \%)$ were $\geq 20$ years of age. The mean ages of the participants with asthma and allergic rhinitis were $7.27 \pm 4.07$ and $7.37 \pm 4.1$ years, respectively, while the mean ages of those with food allergy and atopic dermatitis were $5.46 \pm 4.23$ and $6.46 \pm 5.12$ years, respectively. 


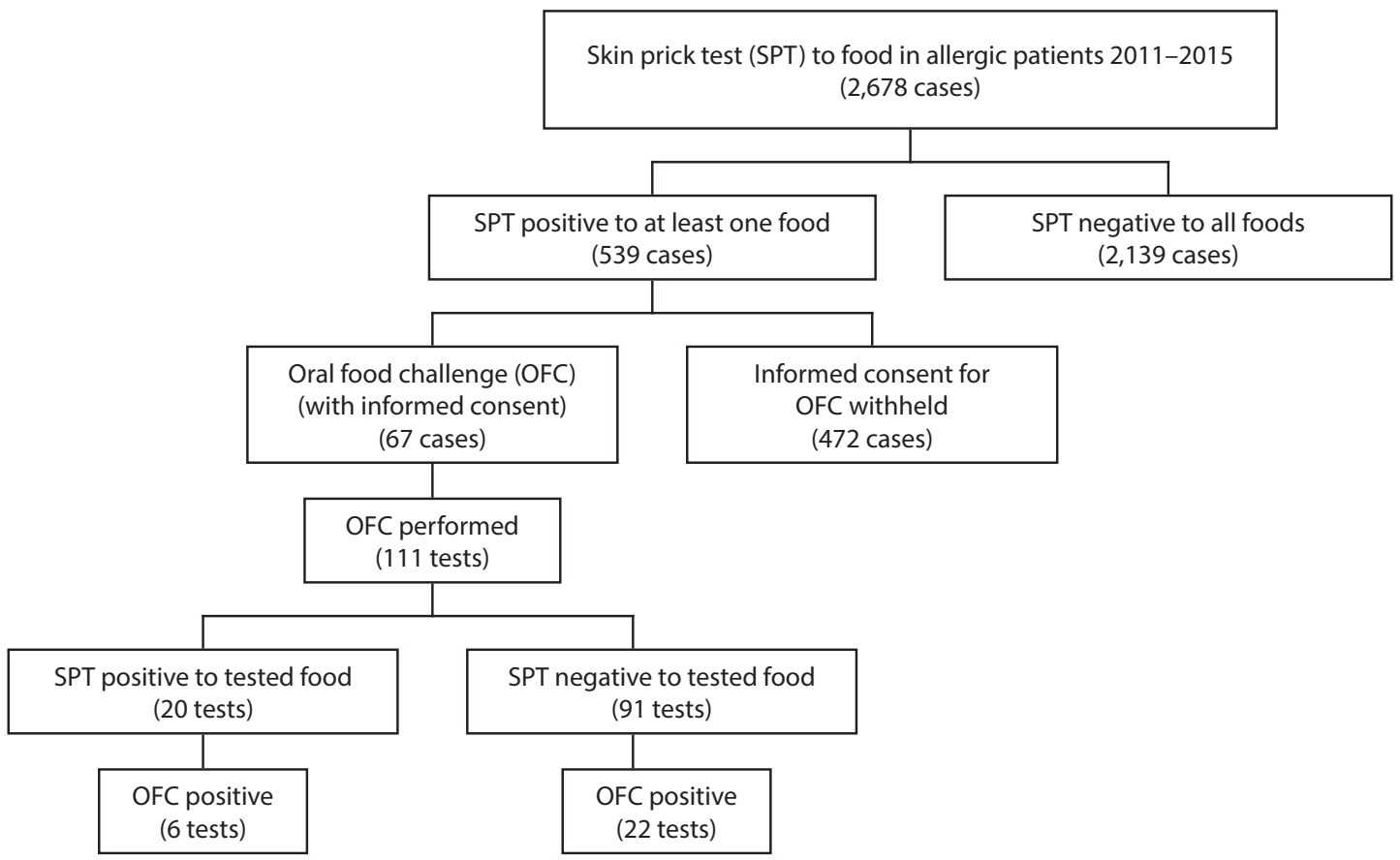

Figure 1.

Table 1. Clinical characteristics of the participants $(n=2,678)$

\begin{tabular}{|lc|}
\hline Characteristics & $\mathbf{n}(\%)$ \\
\hline Male & $1,634(61)$ \\
\hline Mean age, range (years) & $7.2,0.1-29$ \\
\hline Median age (years) & 6.5 \\
\hline Diagnosis & \\
\hline Allergic rhinitis & $2,062(77.0)$ \\
\hline Allergic rhinitis alone & $1,938(72.4)$ \\
\hline Asthma & $452(16.9)$ \\
\hline Asthma alone & $330(12.3)$ \\
\hline Atopic dermatitis & $122(4.6)$ \\
\hline Atopic dermatitis alone & $70(2.6)$ \\
\hline Food allergy & $190(7.1)$ \\
\hline Food allergy alone & $87(3.2)$ \\
\hline Urticaria & $44(1.6)$ \\
\hline Urticaria alone & $30(1.1)$ \\
\hline Allergic conjunctivitis & $40(1.5)$ \\
\hline Allergic conjunctivitis alone & $29(1.1)$ \\
\hline Anaphylaxis & $29(1.1)$ \\
\hline Anaphylaxis alone & $17(0.6)$ \\
\hline Sinusitis & $10(0.4)$ \\
\hline Allergic bronchitis & $9(0.3)$ \\
\hline
\end{tabular}




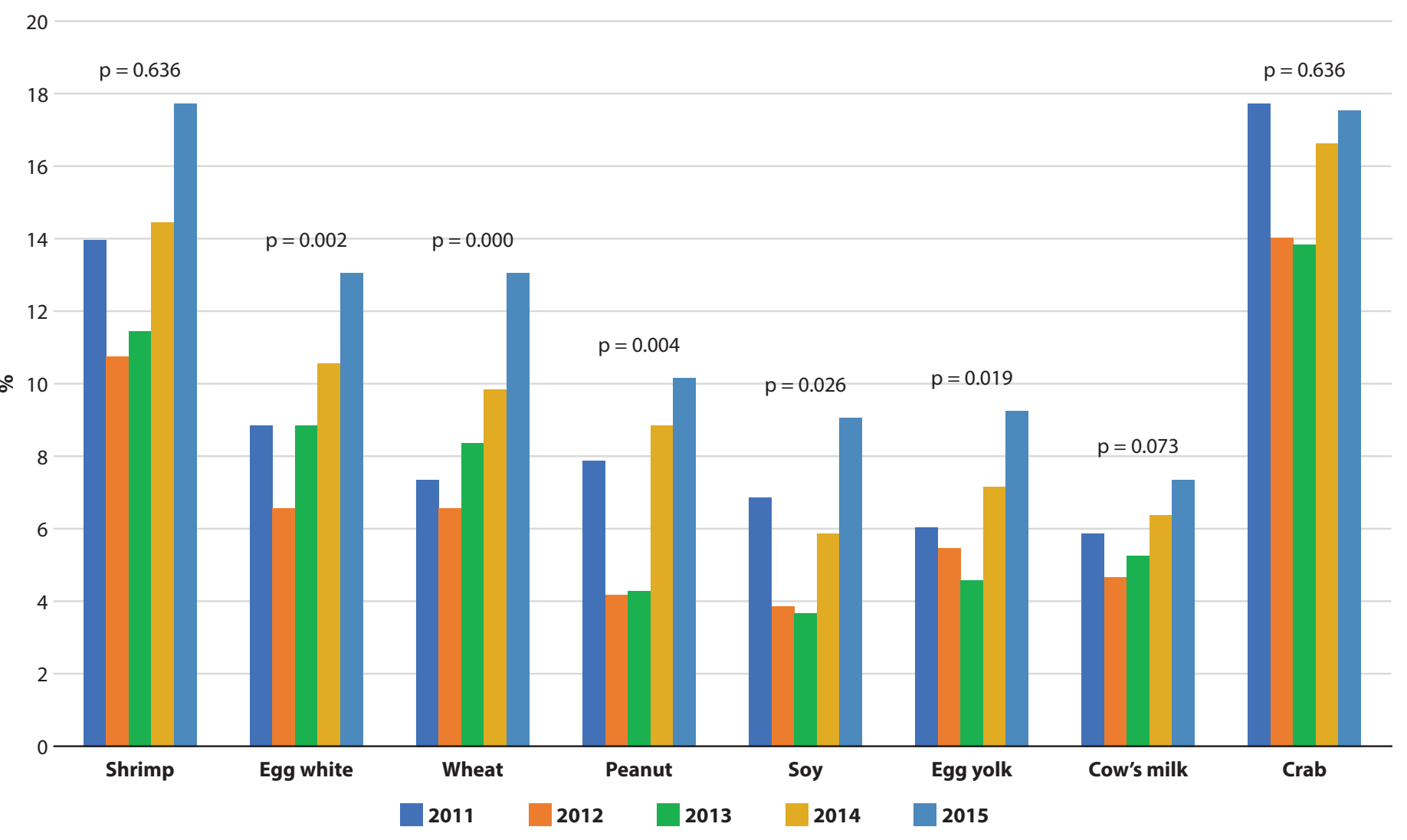

Figure 2.

In the allergic patients, the overall 5-year sensitization to food, as diagnosed by a positive food SPT, was $20 \%$. The percentage of patients with an SPT positive to food in each of the years $2011-2015$ was $21.8 \%, 19.1 \%, 16.8 \%, 21 \%$ and $24.2 \%$, respectively. The foods that showed positive SPT results were crab (15.7\%), shrimp (12.4\%), egg white (9.3\%), wheat $(8.8 \%)$, peanut $(6.5 \%)$, egg yolk (6.2\%), cow's milk (5.7\%), and soy (5.5\%). The percentage of positive SPTs to food antigens in each year from 2011 to 2015 are at Figure 2. Crab was the most common food that the allergic patients were sensitized to, both in each year from 2011-2015 as well as overall during that five-year period, followed by shrimp, egg white, wheat, and peanut.

At the age of $\leq 1$ year, the most common sensitized food was egg white $(23.8 \%$ of the total positive SPTs to food), followed by wheat (22.2\%), egg yolk (12.7\%), cow's milk (6.3\%), and soy $(6.3 \%)$. At the age of $>10$ years, the most common sensitized food was shrimp (21.2\%), followed by crab (18.2\%). Between 1-10 years of age, the most common sensitized foods were crab (44.3\%), egg white (31.8\%), shrimp (24.7\%), and wheat $(24.6 \%)$. Polysensitization (i.e., a positive SPT to more than one food) was more common than monosensitization in the five-year period (64.2\% vs. $35.8 \%$ ). Monosensitization was found in $27.6 \%$ of the positive SPTs to food in $2011,42.1 \%$ in $2012,41.7 \%$ in $2013,36.6 \%$ in 2014 , and $28.2 \%$ in 2015.
A positive OFC was found in $29(26.1 \%)$ out of the 111 OFCs performed. The number of challenges for each food type and the positive test results are detailed at Table 2. The most common foods for which an OFC was performed were cow's milk (29 tests, 23.4\%), followed by wheat (22 tests, $19.8 \%$ ). Positive results were found in $60 \%$ of the crab OFCs, $35.7 \%$ of the egg yolk OFCs, and $31 \%$ of the cow's milk OFCs. Four peanut OFCs were performed, but none were positive.

Table 2. Positive oral food challenge (OFC) results

\begin{tabular}{lccc} 
& & \multicolumn{2}{c}{ Positive } \\
\cline { 3 - 4 } & Number OCT & Number & $\%$ \\
\hline Cow's milk & 29 & 9 & 31.0 \\
\hline Wheat & 22 & 5 & 22.7 \\
\hline Egg white & 15 & 4 & 26.7 \\
\hline Egg yolk & 14 & 5 & 35.7 \\
\hline Soy & 13 & 2 & 15.4 \\
\hline Shrimp & 9 & 1 & 1.1 \\
\hline Crab & 5 & 3 & 60.0 \\
\hline Peanut & 4 & 0 & 0 \\
\hline Total & 111 & 29 & 26.1 \\
\hline
\end{tabular}


Table 3. Sensitivity, specificity, accuracy, test prevalence, likelihood ratio (LR) + and LR- of skin prick test results, compared to oral food challenge results as the gold standard

\begin{tabular}{lcccccc} 
& $\begin{array}{c}\text { Sensitivity } \\
\%\end{array}$ & $\begin{array}{c}\text { Specificity } \\
\%\end{array}$ & $\begin{array}{c}\text { Accuracy } \\
\%\end{array}$ & $\begin{array}{c}\text { Test prevalence } \\
\%\end{array}$ & LR + & LR- \\
\hline Cow's milk & 22 & 85 & 66 & 17 & 1.46 & 0.91 \\
\hline Egg white & 25 & 82 & 67 & 20 & 1.47 & 0.91 \\
\hline Egg yolk & 0 & 89 & 57 & 7 & 0 & 1.12 \\
\hline Soy & 0 & 91 & 77 & 8 & 0 & 1.1 \\
Wheat & 40 & 71 & 64 & 32 & 1.37 & 0.85 \\
\hline Shrimp & 0 & 100 & 89 & 0 & 0 & 1.0 \\
\hline Crab & 50 & - & 50 & 50 & - & - \\
\hline
\end{tabular}

A comparison of the sensitivities, specificities, accuracies, test prevalence, likelihood ratios $(\mathrm{LR})+$, and LR- of the SPT results to the OFCs as the gold standard is at Table 3. The results indicated that SPT to food (cow's milk, egg white, egg yolk, soy, wheat, and shrimp) had high specificity $(71 \%-100 \%)$ but low sensitivity $(0 \%-40 \%)$. The LR+ and LRshowed that an SPT was not an accurate investigative tool for the diagnosis of food allergy, compared to an OFC. The SPT MWDs of participants with a positive OFC to egg white, cow's milk, and wheat were larger than those with a negative OFC (3.75 vs. $0.72 \mathrm{~mm}, 0.89$ vs. $0.50 \mathrm{~mm}$, and 3.20 vs. $1.12 \mathrm{~mm}$, respectively). However, the differences were not statistically significant $(p=0.49-0.80)$.

In the case of the 452 asthmatic patients, the most common foods with a positive SPT were crab (18.6\%) and shrimp (15.7\%), followed by egg white $(9.7 \%)$, soy $(6.9 \%)$, peanut (6.9\%), egg yolk (6.4\%), wheat (5.3\%), and cow's milk (4.4\%). OFC was performed in 11 asthmatic patients, which resulted in $9.1 \%$ positivity. As to the 2,062 allergic rhinitis patients, the most common foods with a positive SPT were crab $(15.8 \%)$ and shrimp (12.7\%), followed by egg white $(8.7 \%)$, wheat (8.7\%), peanut (6.2\%), egg yolk (5.9\%), cow's milk (5.7\%), and soy $(5.1 \%)$. OFC was performed in 35 allergic rhinitis patients and was positive in $28.6 \%$. In the patients with allergic rhinitis alone without other allergy, OFC to food was positive in $42.8 \%(6 / 14)$. The most common foods with a positive SPT in 122 atopic dermatitis patients were crab (17.3\%), egg white $(15.6 \%)$, shrimp (13.1\%), peanut (13.1\%), and wheat (10.7\%), followed by soy $(9.0 \%)$, cow's milk $(7.4 \%)$, and egg yolk (7.4\%). OFC was performed in 23 atopic dermatitis patients and showed $13.0 \%$ positivity. In the case of the 190 food allergy patients, the most common foods with a positive SPT were crab (25.8\%), egg white (18.4\%), egg yolk (14.2\%), wheat (14.2\%), shrimp (13.2\%), and peanut (12.7\%), followed by cow's milk (7.9\%), and soy (5.3\%). OFC was performed in 76 food allergy patients and was positive in $26.3 \%$ of the patients. The most common causative food of food allergy (positive OFC) in respiratory allergic patients were wheat and cow milk followed by egg yolk and crab. In the patients diagnosed as having food allergy, the most common causative food of food allergy were cow milk and egg white followed by egg yolk and wheat.

The trend of food sensitivity in allergic patients from 2011 to 2015 is illustrated at Figure 3. The percentage of sensitization to egg white, egg yolk, wheat, soy, and peanut significantly increased $(p<0.05)$.
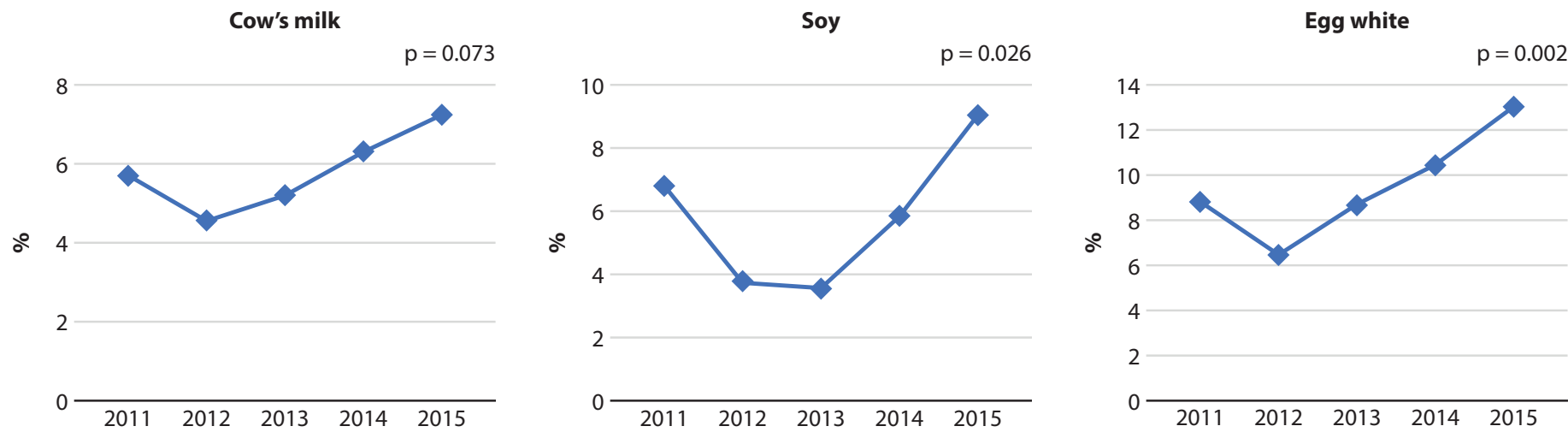

Figure 3. 


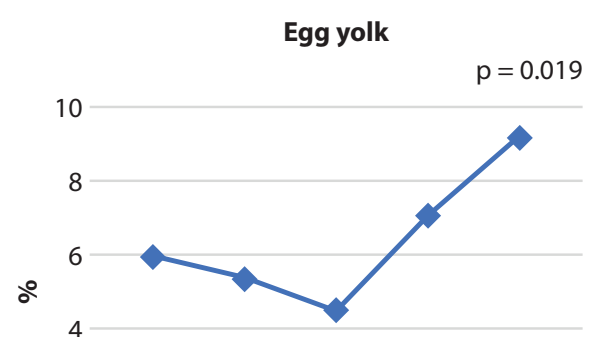

4

2
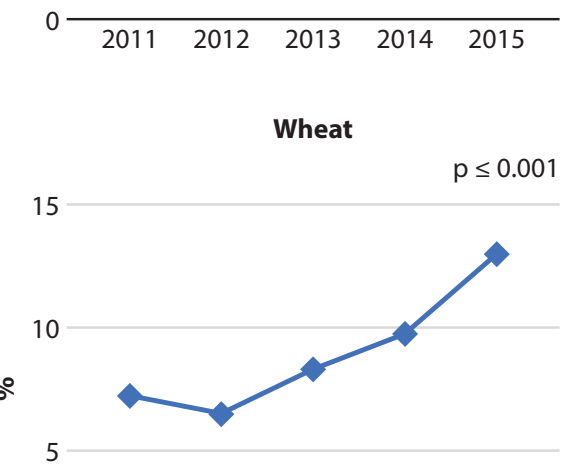

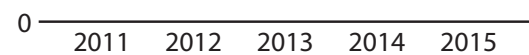

Shrimp

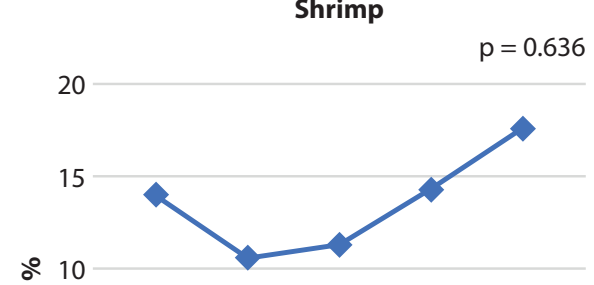

5

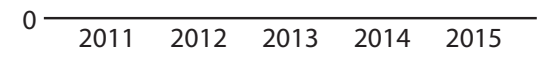

Peanut

15

$p=0.004$

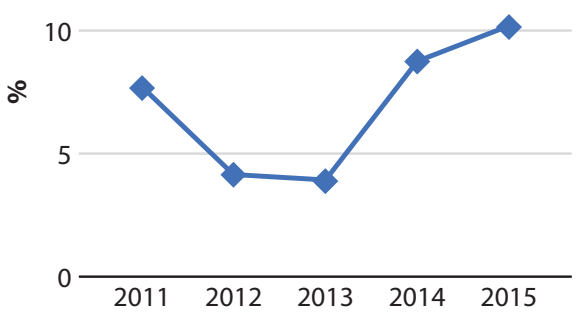

Crab

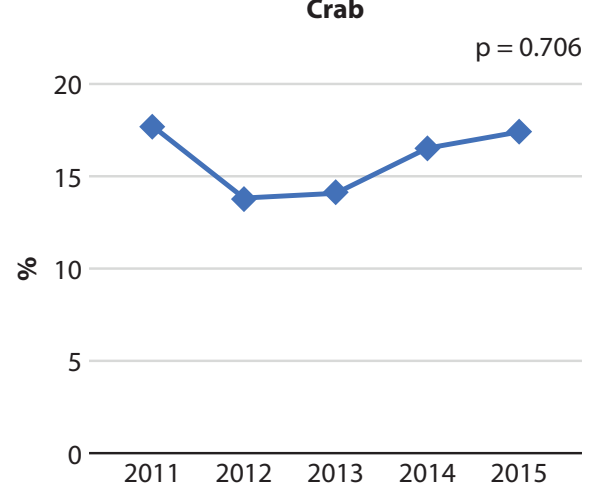

Figure 3. (Continued)

\section{Discussion}

From this study, SPTs using food allergens were positive in $20 \%$ of the participating allergic Thai patients. Crab and shrimp showed SPT positivity in more than $10 \%$ of the SPTs that were undertaken. The reason why seafood was commonly sensitized in this study might be the availability of, and local preference for, seafood in Thailand. This study included patients aged 0.1-29 years, with a median age of 6.5 years. Most of the participants $(73.8 \%)$ were below 10 years of age. At the age $\leq 1$ year, the most common sensitized foods were egg white, wheat, and egg yolk, while at the age $>10$ years, the most common sensitized food was shrimp. Between 1 and 10 years of age, the most common sensitized foods were crab, egg white, shrimp, and wheat. The prevalence of seafood sensitization increased when the participant's age increased.

There is an accordance between our study and a recent study from Japan, in that both showed that the most common food to cause food allergy varied with age. From the Japanese study, at the age of $<1$ year, the most common food was hen egg, followed by cow's milk and wheat. Children who were one year old were most commonly sensitized to hen egg, followed by fish roe and cow's milk. At 2-3 years of age, the most common food to cause sensitization changed to fish roe, followed by hen egg and peanut. At 4-6 years of age, fruit was the most common atopy-inducing food, followed by hen egg and peanut. At 7-19 years of age, the most common food to cause sensitization was crustacean, followed by fruit and hen egg. After 20 years of age, the most common food to induce atopy was wheat, followed by fish and crustacean. ${ }^{14}$
Two previous studies showed that children outgrow egg and milk allergies by the age of 6 in approximately $50 \%$ of cases. ${ }^{15-16}$ The outgrowth of an allergy to some food might explain why the overall, most common sensitized food in our study was seafood since seafood is not commonly outgrown in childhood. A fish or shellfish allergy was reported for $2.3 \%$ of the general population, or approximately 6.6 million Americans, ${ }^{17}$ and it was more common among adults than children $(2.8 \%$ vs $0.6 \% ; p<0.001) .{ }^{17}$

This study demonstrated that the prevalence of polysensitization was more common than monosensitization, with a ratio of $2: 1(64.2 \%$ vs. $35.8 \%)$. This is supported by previous studies in children that reported that polysensitization was more common than monosensitization for both food and aeroallergens. ${ }^{18-20}$

The total percentages of sensitization to food among the patients with asthma, allergic rhinitis, atopic dermatitis, or food allergy were not significantly different. The difference was the kinds of sensitized food. In individuals with asthma and/ or allergic rhinitis, the most commonly sensitized foods were seafood (crab and shrimp). In patients with atopic dermatitis, the most commonly sensitized foods were crab, egg white, shrimp, and peanut. By comparison, food allergy patients were most commonly sensitized to crab, egg white, egg yolk, wheat, shrimp, and peanut. This finding might be explained by the difference in the distribution of the age groups for each disease. Patients with atopic dermatitis and food allergy were younger than those with asthma and allergic rhinitis. 
The frequency of food sensitization among asthmatic children has been reported to be higher than in the general population. ${ }^{21}$ In the case of asthmatic patients, positive specific IgE antibodies $(>0.35 \mathrm{kU} / \mathrm{L})$ to at least one of six allergenic foods (egg, milk, soy, peanut, wheat, and fish) were found in $45 \%$ of the studied individuals. ${ }^{21}$ Another study showed that symptomatic sensitization to food was associated with asthma both in children $<6$ and $>6$ years of age, especially in children with an allergy to more than two types of food or with severe food allergies. ${ }^{22}$

The study showed that only 111 OFCs were performed in 539 positive food SPT patients. The reason why the patients/ parents did not allow the performance of an OFC was either awareness of the potentially severe allergic reactions, or some of the patients could already take the sensitized food without displaying any reactive symptoms. OFC positivity was found in $26.1 \%$ of the overall OFCs, and the most common food that was positive was crab (60\% of the crab OFCs). A previous study in Thai children aged 4 months to 17 years showed 27.5\% positive OFCs, with shrimp being the most common OFC positive food (40\%). ${ }^{23} \mathrm{~A}$ study in Japan established that in infants $<1$ year of age, the most common positive OFC was hen egg (62.1\%), followed by cow's milk (20.1\%) and wheat $(7.1 \%)$. At 2 years of age, fish, peanut, and crustacean were added to the list of most common allergy-induced foods, and at the age of over 7 years, crustacean was the most common cause of food allergy (16\%), followed by hen egg $(15.2 \%) .{ }^{24}$ In this study food allergy was diagnosed in $9.1 \%$ of OFC performed in the patients with asthma, $28.6 \%$ of the patients with allergic rhinitis and $26.3 \%$ in the patients previous diagnosis as having food allergy.

When comparing the SPT results to those of the OFCs (as the gold standard), SPT to food had high specificity $(71 \%-$ $100 \%)$ but low sensitivity $(0 \%-40 \%)$. The LR+ and LR- data showed that SPT was not an accurate investigative tool for the diagnosis of food allergy. This result substantiated that OFC remains the only definitive method for the confirmation of food allergy. ${ }^{25}$

In this study, the MWDs of the SPTs in those with a positive OFC to egg white, cow's milk, and wheat were larger than the MWDs of the SPTs in those with a negative OFC, but the difference was not significant. A previous study showed that for all age groups, the value of $5 \mathrm{~mm}$ for an SPT was found to be significant with a $96.4 \%$ positive predictive value (PPV) and $97.8 \%$ specificity. ${ }^{26}$ Another study performed in 5,276 infants showed SPT thresholds with 95\% PPVs for food allergy were $8 \mathrm{~mm}$ or greater for peanut (95\% CI, 7-9 mm), $4 \mathrm{~mm}$ or greater for egg (95\% CI, 3-5 $\mathrm{mm})$, and $8 \mathrm{~mm}$ or greater for sesame (95\% CI, 5-9 mm). ${ }^{27}$ A further study showed the predictive decision point for an egg white wheal was $9.5 \mathrm{~mm}$, for a milk wheal was $9.5 \mathrm{~mm}$, and for a wheat wheal was $6.5 \mathrm{~mm}$, but their highest accuracy rates were low at $25.8 \%, 26.8 \%$, and $34.4 \%$, respectively. ${ }^{28}$

This study identified that the percentage of sensitization to egg white, egg yolk, wheat, soy, and peanut significantly increased $(p<0.05)$ in allergic patients from 2011-2015. A previous study also showed an increase in food allergy, especially among severe cases with anaphylaxis. ${ }^{29}$
Though there were a considerable number of participants in our study, the number of patients in some age groups were insufficient, and an OFC was not done in all cases of a positive SPT. A distinctive feature of this study was the utilization of local food extracts; these had been previously validated and found to be better than commercial food allergen extracts and comparable with fresh food. ${ }^{10-11}$ In children aged from 2 months to 6 years, fresh food SPTs showed excellent sensitivity $(50 \%-100 \%)$ and a significant correlation with an open OFC $(p<0.001) .{ }^{30}$ Another strong point of this study was the performance of an OFC to confirm food allergy.

This study showed that food sensitization and food allergy in Thai allergic patients was quite common. The sensitization to some foods increased. It also affirmed that food allergy should confirmed by OFC. The SPT to food extracts showed high specificity compared with an OFC for the diagnosis of food allergy.

\section{Conclusion}

The SPTs to food allergens were positive in $20 \%$ of allergic Thai patients. With patients aged $\leq 1$ year, the most common sensitized foods were egg white and wheat, but for patients aged $>10$ years, it was shrimp. The sensitization to egg white, egg yolk, wheat, soy, and peanut significantly increased from 2011 to 2015. Food allergy (positive OFC) in patient with allergic rhinitis was as common as food allergy in patient with clinical diagnosis as having food allergy.

\section{Acknowledgments}

The authors gratefully acknowledge Ms. Julaporn Pooliam for assistance with the statistical analysis.

\section{Conflicts of interest}

None

\section{Funding sources}

This study was supported by a Research Development Fund and a Chalermprakait Grant from the Faculty of Medicine at Siriraj Hospital (Mahidol University, Thailand), and by an NSTDA Chair Professor Grant (P-1450624), funded by the Crown Property Bureau.

\section{References}

1. Asher MI, Montefort S, Björkstén B, Lai CK, Stranchan DP, Weiland SK, et al. Worldwide time trends in the prevalence of symptoms of asthma, allergic rhinoconjunctivitis, and eczema in childhood: ISAAC Phase One and Three repeat multicountry cross-sectional surveys. Lancet. 2006;368:733-43.

2. Wong GW, Leung TF, Fok TF. ISAAC and risk factors for asthma in the Asia-Pacific. Paediatr Respir Rev. 2004;5 Suppl A:S163-9.

3. Li J, Huang Y, Lin X, Zhao D, Tan G, Wu J, et al. Influence of degree of specific allergic sensitivity on severity of rhinitis and asthma in Chinese allergic patients. Respir Res. 2011;12:95.

4. Lao-araya M, Trakultivakorn M. Prevalence of food allergy among preschool children in northern Thailand. Pediatr Int. 2012;54(2):238-43.

5. Santadusit S, Atthapaisalsarudee S, Vichyanond P. Prevalence of adverse food reactions and food allergy among Thai children. J Med Assoc Thai. 2005;88(Suppl 8):S27-32. 
6. Reid MJ, Lockey RF, Turkeltaub P, Platts-Mills TA. Survey of fatality from skin testing and immunotherapy 1985-1989. J Allergy Clin Immunol. 1993;92:6-15.

7. Turkeltaub PC, Gergen PJ. The risk of adverse reactions from percutaneous prick-puncture allergen skin testing, venipuncture, and body measurements: data from the Second National Health and Nutrition Examination Survey 1976-80 (NHANES II). J Allergy Clin Immunol. 1989;84:886-90.

8. Lin MS, Tanner E, Lynn J, Friday Jr. GA. Nonfatal systemic allergic reactions induced by skin testing and immunotherapy. Ann Allergy. 1993;71:557-62.

9. Bunnag C, Jareoncharsri P, Tunsuriyawong P, Assanasen P, Voraprayoon $\mathrm{S}$, Dachpunpour $\mathrm{P}$, et al. Adverse reactions to allergen injection: The Siriraj experience. Siriraj Hosp Gaz. 2002;54:517-23.

10. Visitsunthorn N, Chatpornvorarux S, Pacharn P, Jirapongsananuruk O. Atopy patch test in children with atopic dermatitis. Ann Allergy Asthma Immunol. 2016;117(6):668-73.

11. Boonyaviwat $\mathrm{O}$, Pacharn $\mathrm{P}$, Jirapongsananuruk $\mathrm{O}$, Vichyanond $\mathrm{P}$, Visitsunthorn N. Role of atopy patch test for diagnosis of food allergy-related gastrointestinal symptoms in children. Pediatr Allergy Immunol. 2015;26(8):737-41.

12. van Weel C, Bateman ED, Bousquet J, Reid J, Grouse L, Schermer T, et al. Asthma management pocket reference 2008. Allergy. 2008;63:997-1004.

13. Bousquet J, Van Cauwenberge P, Khaltaev N; ARIA Workshop Group; World Health Organization. Allergic rhinitis and its impact on asthma. J Allergy Clin Immunol. 2001;108(5 Suppl):S147-334.

14. Imai T, Sugizaki C, Ebisawa M. [A report on 2011 nationwide survey of immediate type food allergies in Japan (supported by a grant from "consumer affairs agency, government of Japan")]. Arerugi. 2016;65(7): 942-6. Japanese.

15. Sicherer SH, Wood RA, Vickery BP, Jones SM, Liu AH, Fleischer DM, et al. The natural history of egg allergy in an observational cohort. J Allergy Clin Immunol 2014;133:492e9.

16. Wood RA, Sicherer SH, Vickery BP, Jones SM, Liu AH, Fleischer DM, et al. The natural history of milk allergy in an observational cohort. J Allergy Clin Immunol 2013;131:805e12.

17. Sicherer SH, oz-Furlong AM, Sampson HA. Prevalence of seafood allergy in the United States determined by a random telephone survey. J Allergy Clin Immunol 2004;114:159-65.
18. Gonzales-Gonzalez VA, Diaz AM, Fernandez K, Rivera MF. Prevalence of food allergens sensitization and food allergies in group of allergic Honduran children. Allergy Asthma Clin Immunol. 2018;14:23.

19. Kim NY, Kim GR, Kim JH, Baek JH, Yoon JW, Jee HM, et al. Food allergen sensitization in young children with typical signs and symptoms of immediate-type food allergies: a comparison between monosensitized and polysensitized children. Korean J Pediatr. 2015;58(9):330-5.

20. de Jong AB, Dikkeschei LD, Brand PL. Sensitization patterns to food and inhalant allergens in childhood: a comparison of non-sensitized, monosensitized, and polysensitized children. Pediatr Allergy Immunol. 2011;22(2):166-71.

21. Wang J, Visness CM, Sampson HA. Food allergen sensitization in inner city children with asthma. J Allergy Clin Immunol. 2005;115(5):1076-80.

22. Schroeder A, Kumar R, Pongracic JA, Sullivan CL, Caruso DM, Costello J, et al. Food allergy is associated with an increased risk of asthma. Clin Exp Allergy. 2009;39(2):261-70.

23. Srisuwatchari W, Vichyanond P. Oral food challenges: result of 16-year experience at a major teaching hospital in Thailand. Asia Pac Allergy. 2018;8(2):e21.

24. Akiyama $H$, Imai $T$, Ebisawa $M$. Japan food allergen labeling regulation-history and evaluation. Adv Food Nutr Res. 2011;62:139-71.

25. Gupta M, Cox A, Nowak-Węgrzyn A, Wang J. Diagnosis of food allergy. Immunol Allergy Clin North Am. 2018;38(1):39-52.

26. Nacaroglu HT, Erdem SB, Karaman S, Dogan D, U Karkiner CS, T Kanık E, et al. Diagnostic values for egg white specific IgE levels with the skin prick test in Turkish children with egg white allergy. Allergol Immunopathol (Madr). 2017;45(5):445-51.

27. Peters RL, Allen KJ, Shyamali C. Dharmage SC, Tang MLK, Koplin JJ, et al. Skin prick test responses and allergen-specific IgE levels as predictors of peanut, egg, and sesame allergy in infants. J Allergy Clin Immunol. 2013;132:874-80

28. Imai T, Yanagida N, Ogata M, Komata T, Tomikawa M, Ebisawa M. The skin prick test is not useful in the diagnosis of the immediate type food allergy tolerance acquisition. Allergology International. 2014;63:205-10.

29. Sampson HA. Food allergy: Past, present and future. Allergology International. 2016;65:363-9.

30. Živanović M, Atanasković-Marković M, Medjo B, Gavrović-Jankulović M, Smiljanić K, Tmušić V, et al. Evaluation of food allergy in children by skin prick tests with commercial extracts and fresh foods, specific IgE and, open oral food challenge: Our five years experience in food allergy work-up. Iran J Allergy Asthma Immunol. 2017; 16(2):127-32. 